\title{
Renal Involvement in Sarcoidosis
}

Key words: sarcoidosis, renal involvement, granulomatous nephritis, calcium metabolism, vitamin D

Sarcoidosis is a systemic disease characterized by a noncaseating granulomatous reaction of unknown cause. The disease can be self-limited or chronic, with episodic recrudescence and remission. Because the lungs and thoracic lymph nodes are almost always involved, most patients have respiratory problems, variably accompanied by symptoms affecting the skin, eyes, or other organs. Recent progress in immunology and molecular biology has advanced our understanding of the pathogenesis of the disease and causative agents, which has improved our ability to diagnose and treat this disease (1).

The causative agent or agents have not been identified, and the granulomatous reaction is believed to represent an immunologic hypersensitivity to widely disseminated antigens that either have a low solubility or that cannot be metabolized. High titers of antibody to a number of viruses and other organisms have been reported in sarcoidosis. Circulating immune complexes can be identified in up to $50 \%$ of cases, but their pathogenetic role is not clear. However, recent data suggest that propionibacteria reside or proliferate ectopically in the sarcoid lesions. Propionibacteria is a more likely candidate of such an antigen (2).

Macrophage and $\mathrm{T}$ cell activation appear to be central to granuloma formation. In sarcoidosis, macrophages spontaneously release interleukin (IL)-1, and on stimulation they release enhanced quantities of tumor necrosis factor (TNF) and reactive oxygen intermediates. T cells demonstrate active proliferation and spontaneous secretion of several cytokines such as interleukin -2 and interferon (IFN) $\gamma$.

Extensive biopsy and post-mortem studies have shown that granulomatous renal involvement is present in only 4 to 20 percent of all patients with sarcoidosis. Primary glomerular disease has been observed with much less frequency, despite the increasing number of reports (3-8). Renal involvement in sarcoidosis can be divided into three groups as follows: nephropathy due to aberrant calcium metabolism, sarcoid interstitial nephritis and sarcoid glomerulopathy $(7,9)$.

\section{Nephropathy due to aberrant calcium metabolism}

Hypercalcemia occurs in $10 \%$ to $20 \%$ of all patients with sarcoidosis. Numerous reports document that impaired renal function is most marked in patients with hypercalcemia. The mechanism by which hypercalcemia impairs the glomerular filtration rate (GFR) include nephrocalcinosis, nephrolithiasis with secondary obstruction or infection, and the hemodynamic effects of hypercalcemia on renal blood flow and the glomerular capillary ultrafiltration coefficient. Recent data have also emphasized the role of 1,25-dihydroxyvitamin D3. Macrophages, probably under the influence of IFN $\gamma$ acquire 25hydroxyvitamin D3, $\alpha 1$-hydroxylase activity. The overproduction of 1,25-dihydroxyvitamin D3 may cause increased intestinal absorption of calcium, enhanced bone resorption, and resultant hypercalciuria with or without hypercalcemia. This process can ultimately result in nephrocalcinosis and renal failure $(9,10)$.

\section{Sarcoid interstitial nephritis}

More common renal manifestations of sarcoidosis include interstitial nephritis, interstitial fibrosis, nephrolithiasis, obstructive uropathy, and abnormalities of tubule function including nephrogenic diabetes inspidus and renal tubular acidosis. Interstitial inflammation with non-caseating granulomas, epithelioid and multinucleated giant cells is the usual histologic picture. Intimal thickening is not infrequent and granulomas may occasionally involve the small arteries. Immunofluorescence and electron microscopic findings are non-specific. Although sarcoid granuloma may be found in the kidneys in $15 \%$ to $40 \%$ of patients with sarcoidosis, renal dysfunction due to solely to granulomatous infiltration is a rare clinical finding. Finally, in a number of patients with sarcoidosis, severe interstitial nephritis, granulomas, and progressive fibrosis have led to renal insufficiency and to death from uremia (11-18). In this issue, Ohashi et al described a patient with sarcoidosis presenting with acute renal failure (19).

See also p 1171.

Aberrant calcium and vitamin D metabolism associated with granulomatous interstitial nephritis may contribute to acute renal failure.

\section{Sarcoid glomerulopathy}

Numerous histopathologic varieties of glomerular lesions have been reported (20-29). A review of literature disclosed that glomerular pathology has been reported in 25 patients, including seven with membranous glomerulonephritis, one with membranoproliferative glemerulonephritis, two with focal sclerosis, and two with chronic glomerulonephritis. In these glomeruli, crescents were also prominent features (21). Renal amyloidosis is rarely observed (29).

The pathogenesis of glomerular lesions is unknown. It can be postulated that the defective cellular immunity leads to al- 
tered glomerular permeability and subsequent histologic change. In addition the presence of circulating immune complexes may contribute to the relative high incidence of membranous glomerulonephritis in patients with sarcoidosis. On the other hand, the simultaneous presentation of sarcoidosis and $\operatorname{Ig} \mathrm{A}$ nephropathy has been recognized. A link between $\operatorname{IgA}$ nephropathy and sarcoidosis may exist because of the abnormalities of cellular and humoral immunity thought to be characteristic of both conditions (26-28).

Finally, it is well recognized that corticosteroids are the most effective agents to control hypercalcemia and renal failure induced by granulomatous inflammation. On the contrary, corticosteroid therapy is not recommended in the patients with glomerulonephritis, other than nephrotic membranous glomerulonephritis $(1,9)$.

Kenichi AsaKuRA, MD The Department of Internal Medicine, Yuri General Hospital, 38 Kawaguchi-Yago, Honjo, Akita 015-8511

\section{References}

1) Newman LS, Rose CS, Maier LA. Sarcoidosis. N Engl J Med 336: 1224 1234, 1997.

2) Ishige I, Usui Y, Takemura T, Eishi Y. Quantitative PCR of mycobacterial and propionibacterial DNA in lymph nodes of Japanese patients with sarcoidosis. Lancet 354: 120-123, 1999.

3) Lofgren S, Snellman B, Lindfren AGH. Renal complications in sarcoidosis. Acta Med Scand 159: 295-305, 1957.

4) Mayock RL, Bertrand P, Morrison CE, Scott JH. Manifestations of sarcoidosis. Analysis of 145 patients, with a review of nine series selected from the literature. Am J Med 35: 67-89, 1963.

5) Lebacq E, Desmet V, Verhaegen H. Renal involvement in sarcoidosis. Postgrad Med J 46: 526-529, 1970.

6) Muther RS, McCarron DA, Bennett WM. Renal manifestations of sarcoidosis. Arch Intern Med 141: 643-645,1981.

7) Casella FJ, Allon M. The kidney in sarcoidosis. J Am Soc Nephrol 3: 1555-1562, 1993.

8) MacSearraigh ET, Doyle CT, Twomey M, O'Sullivan DJ. Sarcoidosis with renal involvement. Postgrad Med J 54: 528-532, 1978.

9) Akmal M, Sharma OP. Renal sarcoidosis; a reminder. [editorial] Chest 97: 1284-1285, 1990.

10) Singer FR, Adams JS. Abnormal calcium homeostasis in sarcoidosis. N Engl J Med 315: 755-757, 1986.

11) Klatskin G, Gordon M. Renal complications of sarcoidosis and their relationship to hypercalcemia. Am J Med 15: 484-498, 1953.
12) Coburn JW, Hobbs C, Johnson GS, Richart JH, Shinaberger JH, Rosen S. Granulomatous sarcoid nephritis. Am J Med 42: 273-283, 1967.

13) Muther RS, McCarron DA, Bennett WM. Granulomatous sarcoid nephritis: a cause of multiple renal tubular abnormalities. Clin Nephrol 14: 190197, 1980.

14) Hannedouche T, Grateau G, Noel LH, et al. Renal granulomatous sarcoidosis : Report of six cases. Nephrol Dial Transplant 5: 18-24, 1990.

15) King BP, Esparza AR, Kahn SI, Garella S. Sarcoid granulomatous nephritis occurring as isolated renal failure. Arch Intern Med 136: 241-245, 1976.

16) Boltan WK, Aluk NO, Rametta C, Sturgill BC, Spargo BH. Reversible renal failure from isolated granulomatous renal sarcoidosis. Clin Nephrol 5: 88-92, 1976.

17) Andreoli SP, Kleiman MB, Yum MW, Bergstein JM. Acute eosinophilic interstitial nephritis and sarcoidosis. Arch Pathol Lab Med 105: 626-627, 1981.

18) Cruzado JM, Poveda R, Mana J, et al. Interstitial nephritis in sarcoidosis: simultaneous multiorgan involvement. Am J Kidney Dis 26: 947-951, 1995.

19) Ohashi N, Yonemura K, Hirano M, et al. A patient with sarcoidosis presenting with acute renal failure: Implication for granulomatous interstitial nephritis and hypercalcemia. Intern Med 41: 1171-1174, 2002.

20) Hakaim AG, Stilmant MM, Kauffman J, et al. Successful renal transplantation in a patient with systemic sarcoidosis and renal failure due to focal glomerulosclerosis. Am J Kidney Dis 19: 493-495, 1992.

21) Lee SM, Michael AF. Focal glomerular sclerosis and sarcoidosis. Arch Pathol Lab Med 102: 572-575, 1978.

22) Goldszer RC, Galvanrek EG, Lazarus JM. Glomerulonephritis in a patient with sarcoidosis : Report of a case and review of a literature. Arch Pathol Lab Med 105: 478-481,1981.

23) Taylor TK, Senekjian HO, Knight TF, Gyorkey F, Weinman EJ. Membranous nephropathy with epithelial crescents in a patient with pulmonary sarcoidosis. Arch Intern Med 139: 1183-1185, 1979.

24) Salomon MI, Poon TP, Hsu KC, King EJ, Tchertkoff V. Membranous glomerulopathy in a patient with sarcoidosis. Arch Pathol 99: 479-483, 1975.

25) Khan IH, Simpson JG, Catto GRD, MacLeod AM. Membranous nephropathy and granulomatous interstitial nephritis in sarcoidosis. Nephron 66: 459-461, 1994.

26) Taylor JE, Ansell ID. Steroid-sensitive nephrotic syndrome and renal impairment in a patient with sarcoidosis and IgA nephropathy. Nephrol Dial Transplant 11: 355-356, 1996.

27) Anwar N, Gokal R. Simultaneous occurrence of IgA nephropathy and sarcoidosis in the context of pre-existent minimal change nephrotic syndrome. Nephron 65: 310-312, 1993.

28) Tateno S, Kobayashi Y, Kobayashi F. A case of a sarcoidosis revealed in the course of IgA nephropathy. Pathol Int 44: 387-390, 1994.

29) Rainfray M, Meyrier A, Valeyre D, Tazi A, Battesti JP. Renal amyloidosis complicating sarcoidosis. Thorax 43: 422-423, 1988. 